\title{
Oral Contraceptives, Abortion and Breast Cancer Risk: a Case Control Study in Saudi Arabia
}

\author{
Syed Mustafa Karim ${ }^{1,4 *}$, Wijdan Baeshen ${ }^{2}$, Syed Nehal Neamatullah' ${ }^{3}$, Bakr Bin
}

\begin{abstract}
Background: Several studies have examined the relationship between oral contraceptive pill (OCP) use, abortions and breast cancer, with mixed results. Hormonal changes associated with $\mathrm{OCP}$ use and abortion may increase risk of breast cancer over time, but there is a lack of studies studying this association in Saudi Arabian women. Materials and Methods: We thererfore conducted a case control study in 192 women (92 as cases and 100 as controls), aged 30 to 65 , and collected information on variables including examples related to study objectives and those which may confound findings. The Chi square test was used to detect associations between various factors and risk of breast cancer. Results: We found no evidence of interaction between history of abortion or frequency of abortion and breast cancer risk (Chi square $=0.422, p=0.420$ and $1, p=0.169$ ) respectively. Oral contraceptives did not confer risk for breast cancer overall $(\mathrm{OR}=0.276,95 \% \mathrm{CI} 0.092-0.829, \mathrm{p}=0.524)$, while long term use of OCP was associated with increased risk of breast cancer $(\mathrm{OR}=0.297,95 \% \mathrm{CI}$ 0.158-0.557, $\mathrm{p}=0.001)$, with higher association for those who used 10 years or more of OCPs $(\mathrm{OR}=\mathbf{0 . 2 8 2 , 9 5 \%} \mathrm{CI} \mathbf{0 . 0 9 5 - 0 . 8 3 5}, \mathrm{p}=\mathbf{0 . 0 2})$. Age at first use of OCPs had no effect on breast cancer risk $(p=0.452)$ or age at diagnosis $(p=0.074)$. Conclusions: Prolonged use of OC (more than 10 years) may be associated with increased risk of breast cancer in Saudi women. Larger population based studies are needed to confirm this finding in this population.
\end{abstract}

Keywords: Oral contraceptives - breast cancer risk - abortion - Saudi Arabia

Asian Pac J Cancer Prev, 16 (9), 3957-3960

\section{Introduction}

Breast cancer is the most common cancer affecting women worldwide in both the developed and developing countries (Ferlay et al., 2010). Globally, about 1.4 million new cases are diagnosed each year. About $6.6 \%$ of all breast cancer cases are women less than 40 years of age, $2.4 \%$ less than 35, and $0.65 \%$ less than 30 (Anders et al., 2009; Fredholm et al., 2009). The increase in overall worldwide burden of breast cancer may be attributable to increasing life expectancy and widespread adoption of westernized lifestyle with its associated risk factors (Boyle and Howell, 2010).

According to the Saudi Cancer Registry, breast cancer represents approximately $27.4 \%$ of all cancer cases in Saudi Arabia, making it the most common cancer diagnosis in women. A total of 1473 new breast cancer cases were diagnosed in 2010, translating to an approximately 24.9 per100,000 incidence rate within the female population (Kingdom of Saudi Arabia, 2010).

Theoretically, several factors such as familial genetic mutations, alcohol use, obesity and physical inactivity (ABCSG, 2000; Carmichael and Bates, 2004; Assi et al., 2013) may increase breast cancer risk. In younger women, factors increasing exposure to estrogen also may constitute risk for breast cancer (Danaei et al., 2005; Assi et al., 2013). Estrogen exposure can be endogenous (including early menarche, late menopause, late age at first childbirth) or exogenous, mainly due to OCPs or hormone replacement therapy (Organization; Zhang et al., 2012). Both current and prior exposure to OCPs has been reported to potentially increase breast cancer risk (Cancer, 1996).

There is paucity of data studying hormonal factors as increasing risk for breast cancer in the Middle Eastern populations, particularly in Saudi Arabia. For this reason, we performed a limited case control study to explore the possibility of any such interaction in this population.

\section{Materials and Methods}

Eligible study participants (cases and controls) were women in the range of 30-65 years married or previously married Saudi or non-Saudi and registered in King Faisal Specialist Hospital and Research Centre in Jeddah since 2001 and up to 2013. Eligible controls also include patients' relatives who do not represent hospital patients but met the inclusion criteria.

It was expected that $30 \%$ of controls would be OCP 
users and since our aim was to detect if OCPs (odds ratio $[\mathrm{OR}]=2$ ) (Amin et al., 2009), induced abortion (OR=1.9) and a spontaneous abortion $(\mathrm{OR}=1.5)$ were associated with breast cancer (Howe et al., 1989), the sample size (using power of $90 \%$ and a significance level of 5\%) was calculated to be 189 (for both cases and controls). Convenience sampling technique was used to offer the study to subjects visiting oncology and family medicine outpatient clinics. 92 cases and 100 controls agreed to participate in the study and were interviewed.

Participants were requested to answer information regarding parity, history of breast cancer or any type of cancer, age at first child, menarche, menopause, duration of breastfeeding, physical activity and diet, with detailed information regarding OCP use and abortion incidents. In case of history of breast cancer, oncologic data was retrieved from the medical records after consent from the patients. Demographic data were also collected for all participants.

Data was collected in SPSS version 20. Chi square test was used to detect association between duration of OCP use (no use, less than 3 years, 4 to 9 years, and 10 years or more) and breast cancer incidence or histologic subtype of breast cancer. Pearson correlation was used to assess the correlation of age at breast cancer onset and age at start of OCPs. Binary logistic regression was used to assess the correlation of any other possible risk factors and the degree of their contribution to breast cancer.

\section{Results}

The final study population comprised 192 women (92 cases and 100 controls). The mean age of cases was 49.6 in comparison with control group (45.5) which was observed as significant difference $(\mathrm{p} \leq 0.01)$. Age and $\mathrm{BMI}$ of cases and controls were significantly different with mean difference $4.09(\mathrm{p}=0.01)$ and $1.927(\mathrm{p}=0.04)$ respectively. No significant difference was observed between cases and controls in terms of age at menarche, parity, age at 1 st child, age at menopause and age at first use of oral contraceptives (Table 1).
Table 2. Comparison of Risk Factors in Cases and Controls. $P$ values are from Chi Square Test

\begin{tabular}{|c|c|c|c|}
\hline Factors & $\begin{array}{c}\text { Cases }=92 \\
\mathrm{~N}(\%)\end{array}$ & $\begin{array}{c}\text { Controls }=100 \\
\mathrm{~N}(\%)\end{array}$ & $\mathrm{P}$ value \\
\hline \multicolumn{4}{|l|}{ History of abortion } \\
\hline $\mathrm{Had}$ & $47(51)$ & $57(57)$ & \multirow[t]{2}{*}{0.42} \\
\hline Never & $45(49)$ & $43(43)$ & \\
\hline \multicolumn{4}{|l|}{ Frequency of abortion } \\
\hline$\leq 3$ times & $38(80)$ & $54(94)$ & \multirow[t]{2}{*}{0.17} \\
\hline$>3$ times & $8(20)$ & $5(6)$ & \\
\hline \multicolumn{4}{|c|}{ Use of oral contraceptives } \\
\hline Yes continuously & $39(42)$ & $50(50)$ & \multirow[t]{3}{*}{0.52} \\
\hline Yes intermittently & $15(16)$ & $17(17)$ & \\
\hline No & $37(40)$ & $35(35)$ & \\
\hline \multicolumn{4}{|c|}{ Duration of oral contraceptives } \\
\hline$\leq 3$ years & $16(32)$ & $43(64)$ & \multirow[t]{3}{*}{0.01} \\
\hline 4-9 years & $17(34)$ & $14(20)$ & \\
\hline$\geq 10$ years & $17(34)$ & $10(14)$ & \\
\hline \multicolumn{4}{|c|}{ Family history of cancer } \\
\hline Yes & $41(44.5)$ & $15(15)$ & \multirow[b]{2}{*}{$<0.01$} \\
\hline No & $51(55.4)$ & $85(85)$ & \\
\hline \multicolumn{4}{|l|}{ Menopausal status } \\
\hline Premenopausal & $41(44.5)$ & $55(55)$ & \multirow[t]{2}{*}{0.25} \\
\hline Postmenopausal & $51(55.4)$ & $44(44)$ & \\
\hline \multicolumn{4}{|l|}{ Breastfeeding } \\
\hline Yes & $71(76)$ & $79(79)$ & \multirow[t]{2}{*}{0.63} \\
\hline No & $21(23.9)$ & $21(21)$ & \\
\hline \multicolumn{4}{|c|}{ Duration of breastfeeding } \\
\hline$\geq 6$ months & $47(67)$ & $60(74)$ & \multirow[t]{2}{*}{0.28} \\
\hline$<6$ months & $24(34)$ & $21(26)$ & \\
\hline \multicolumn{4}{|l|}{ Regularity of period } \\
\hline Regular & $70(76)$ & $75(75)$ & \multirow[t]{2}{*}{0.76} \\
\hline irregular & $21(22)$ & $25(25)$ & \\
\hline \multicolumn{4}{|l|}{ Exercise } \\
\hline Yes & $41(44.5)$ & $55(55)$ & \multirow[t]{2}{*}{0.13} \\
\hline No & $51(55.4)$ & $44(44)$ & \\
\hline \multicolumn{4}{|l|}{ Nationality } \\
\hline Saudi & $89(96.7)$ & $95(95)$ & \multirow[t]{2}{*}{0.55} \\
\hline Non Saudi & $3(3.26)$ & $5(5)$ & \\
\hline \multicolumn{4}{|c|}{ Use of Reproductive hormones replacements } \\
\hline Yes & $30(32)$ & $25(25)$ & \multirow[t]{2}{*}{0.26} \\
\hline No & $62(67)$ & $74(74)$ & \\
\hline \multicolumn{4}{|c|}{ Age at first use of oral contraceptives } \\
\hline$\geq 18$ year old & $10(22)$ & $7(11)$ & \multirow[t]{2}{*}{0.11} \\
\hline$<18$ year old & $34(77)$ & $55(88)$ & \\
\hline
\end{tabular}

Table 1. Patient Characteristics in Two Cohorts, with Differences in Means Expressed as t-test Values and p values with $95 \%$ Confidence Intervals

\begin{tabular}{|c|c|c|c|c|c|c|}
\hline & Study group & $\mathrm{N}$ & mean & $\mathrm{t}$ & $\mathrm{P}$ value & $95 \% \mathrm{CI}$ \\
\hline \multirow[t]{2}{*}{ BMI } & Case & 92 & 32.6 & 2.14 & 0.04 & (0 .13 to 3.73$)$ \\
\hline & Control & 82 & 30.7 & & & \\
\hline \multirow[t]{2}{*}{ Age } & Case & 92 & 49.6 & 3.23 & $<0.01$ & (1.59 to 6.50$)$ \\
\hline & Control & 100 & 45.5 & & & \\
\hline \multirow[t]{2}{*}{ Menarche } & Case & 92 & 12.9 & -0.35 & 0.72 & $(-0.53$ to -0.37$)$ \\
\hline & Control & 100 & 13.1 & & & \\
\hline \multirow[t]{2}{*}{ Parity } & Case & 81 & 4.75 & -0.88 & 0.38 & $(-1.08$ to 0.42$)$ \\
\hline & Control & 94 & 5.09 & & & \\
\hline \multirow[t]{2}{*}{ Age at 1 st child } & Case & 80 & 21.7 & 0.54 & 0.59 & $(-1.23$ to -2.16$)$ \\
\hline & Control & 93 & 21.2 & & & \\
\hline \multirow[t]{2}{*}{ age at menopause } & Case & 43 & 48.6 & 1.17 & 0.24 & $(-1.225$ to 4.726$)$ \\
\hline & Control & 26 & 46.8 & & & \\
\hline \multirow[t]{2}{*}{ Age at 1 st use of OCPs } & Case & 44 & 23.9 & -0.75 & 0.45 & $(-3.09$ to 1.39$)$ \\
\hline & Control & 62 & 24.8 & & & \\
\hline \multirow[t]{2}{*}{ Age at diagnosis } & Case & 92 & 47.1 & & 0.72 & \\
\hline & Control & & & & & \\
\hline
\end{tabular}


Table 3. Results of Stepwise Logistic Regression Analysis

\begin{tabular}{|c|c|c|}
\hline Factors & $\mathrm{P}$ value & OR $(95 \% \mathrm{CI})$ \\
\hline \multicolumn{3}{|c|}{ Duration of oral contraceptives } \\
\hline$(\leq 3$ years $)$ & 0.05 & \\
\hline (4-9 years) & 0.08 & $0.39 \quad(0.14-1.11)$ \\
\hline$(\geq 10$ years $)$ & 0.02 & $0.28 \quad(0.09-0.83)$ \\
\hline Family history & $<0.01$ & $4.05 \quad(1.57-10.4)$ \\
\hline BMI & 0.78 & $0.988(0.91-1.07)$ \\
\hline Age & 0.04 & $0.95 \quad(0.89-0.99)$ \\
\hline
\end{tabular}

Table 2 shows comparison between cases and controls by numbers and percentages of some demographics data and factors presumed to be associated with breast cancer risk. Family history of breast cancer was seen in $44.5 \%$ of breast cancer patients compared to only $15 \%$ of controls $(\mathrm{p}<0.01)$. From 92 breast cancer patients, $51 \%$ had abortion and $80 \%$ of them aborted 3 times or less, while from controls $57 \%$ of 100 patients had history of abortion ( $94 \%$ of them had aborted 3 times or less). There was no evidence of interaction between history of abortion $(p=0.422)$ or frequency of abortion $(p=0.169)$ and breast cancer incidence.

OCP users accounted for $58 \%$ of cases and $67 \%$ of controls, (including both continuous and intermittent users). Of these, $34 \%$ of cases and $24 \%$ of controls used OCPs for more than 3 years respectively. Chi square test showed no association between history of OCP use and incidence of breast cancer $(\mathrm{OR}=0.276,95 \% \mathrm{CI}$ $0.092-0.829 ; \mathrm{p}=0.524)$. However, longer term use of oral contraceptives did show association with incidence of breast cancer $(\mathrm{OR}=0.297,95 \%$ CI $0.158-0.557 ; \mathrm{p}=0.001)$. In the breast cancer cohort, there was no correlation between duration of OCP use and the phenotypic subtypes of breast cancer.

All factors were entered into stepwise logistic regression analysis. Factors that retained significance with breast cancer were age, family history and duration of oral contraceptive use (Table 3 ).

\section{Discussion}

Studies aimed at finding correlations between hormonal risk factors and breast cancer incidence have varied in their results. While smaller studies have shown some association (Danaei et al., 2005; Assi et al., 2013), other large studies conducted in the Western population have not confirmed this association (Hankinson et al., 1997; Marchbanks et al., 2002; Hannaford et al., 2007; Vessey and Yeates, 2013). These and another study done in the United States also did not show any effect of race, duration, dose and age of starting contraception on development of breast cancer. A meta-analysis also failed to show such correlation, with relative risk of development of breast cancer of 1.10 (confidence interval of 1.03 to 1.18) with OCP use (Anothaisintawee et al., 2013).

Smaller studies in Eastern populations have also varied in their results. One study in Iranian women for example showed increased incidence of breast cancer with OCPs, and found a correlation between type of oral contraceptive and age at starting the OCP (Vaisy et al., 2014). Another Report from Turkey showed no association between stage IV breast cancer and OCP use (Uyeturk et al., 2013). A study from China showed that reproductive factors such as age at menarche, parity, breastfeeding, menopausal status and abortion history have different effects on the subtypes of breast cancer in their population (Xing et al., 2010).

Although the results of our study also show this lack of correlation overall, we did find prolonged use of OCPs to correlate with breast cancer risk. However, given the small sample size, this needs to be confirmed in a larger study in our population.

Data regarding effect of OCPs on development of breast cancer in high risk populations such as those with family history of breast cancer or those harboring BRCA mutations also have yielded inconsistent results (Moorman et al., 2013). In our study, BRCA status of patients and controls was not available to us, and family history of breast cancer was independently correlated with higher breast cancer risk.

Our study did not show an association of history of abortion with breast cancer. Prior large international population cohort studies have also not shown this association (Beral et al., 2004), even with induced abortions (Melbye et al., 1997; Reeves et al., 2006). We also did not find a correlation between higher number of abortions (more than 3) and breast cancer risk. Our findings mirror international data that abortion related hormonal changes are unlikely to influence development of cancer in the breast tissue.

Limitations of our study include possibility of recall bias due to inconsistency of self-reported data of past exposure which may have affected the results. Another limitation is the small sample size, and a larger registry based population study is required to confirm these results in the Saudi Arabian population.

\section{References}

ABCSG (2000). Prevalence and penetrance of BRCA1 and BRCA2 mutations in a population-based series of breast cancer cases. Anglian breast cancer study group. $\mathrm{Br} J$ Cancer, 83, 1301-8.

Amin TT, Al Mulhim AR, Al Meqihwi A (2009). Breast cancer knowledge, risk factors and screening among adult Saudi women in a primary health care setting. Asian Pac J Cancer Prev, 10, 133-8.

Anders CK, Johnson R, Litton J, et al (2009). Breast cancer before age 40 years. Semin Oncol, 36, 237-49.

Anothaisintawee T, Wiratkapun C, Lerdsitthichai P, et al (2013). Risk factors of breast cancer: a systematic review and metaanalysis. Asia Pac J Public Health, 25, 368-87.

Assi HA, Khoury KE, Dbouk H, et al (2013). Epidemiology and prognosis of breast cancer in young women. $J$ Thorac Dis, 5, 2072-1439.

Beral V, Bull D, Doll R, et al (2004). Breast cancer and abortion: collaborative reanalysis of data from 53 epidemiological studies, including 83 ?000 women with breast cancer from 16 countries. Lancet, $\mathbf{3 6 3}, 1007-16$.

Boyle P, Howell A (2010). The globalisation of breast cancer. Breast Cancer Res, $\mathbf{1 2}, 7$.

Cancer CGoHFiB (1996). Breast cancer and hormonal contraceptives: collaborative reanalysis of individual data 
on 53297 women with breast cancer and 100239 women without breast cancer from 54 epidemiological studies. Lancet, 347, 1713-27.

Carmichael AR, Bates T (2004). Obesity and breast cancer: a review of the literature. Breast, 13, 85-92.

Danaei G, Vander Hoorn S, Lopez AD, et al (2005). Causes of cancer in the world: comparative risk assessment of nine behavioural and environmental risk factors. Lancet, $\mathbf{3 6 6}$, 1784-93.

Ferlay J, Shin HR, Bray F, et al (2010). Estimates of worldwide burden of cancer in 2008: GLOBOCAN 2008. International J Cancer, 127, 2893-917.

Fredholm H, Eaker S, Frisell J, et al (2009). Breast cancer in young women: poor survival despite intensive treatment. PloS one, 4, 7695.

Hankinson SE, Colditz GA, Manson JE, et al (1997). A prospective study of oral contraceptive use and risk of breast cancer (Nurses' Health Study, United States). Cancer Causes Control, 8, 65-72.

Hannaford PC, Selvaraj S, Elliott AM, et al (2007). Cancer risk among users of oral contraceptives: cohort data from the Royal College of General Practitioner's oral contraception study. $B M J, 335,11$.

Howe HL, Senie RT, Bzduch H, et al (1989). Early abortion and breast cancer risk among women under age 40. Int $J$ Epidemiol, 18, 300-4.

Marchbanks PA, McDonald JA, Wilson HG, et al (2002). Oral contraceptives and the risk of breast cancer. $N$ Engl J Med, 346, 2025-32.

Melbye M, Wohlfahrt J, Olsen JH, et al (1997). Induced abortion and the risk of breast cancer. $N$ Engl J Med, 336, 81-5.

Moorman PG, Havrilesky LJ, Gierisch JM, et al (2013). Oral contraceptives and risk of ovarian cancer and breast cancer among high-risk women: a systematic review and metaanalysis. J Clin Oncol, 31, 4188-98.

Organization WH. Breast cancer: prevention and control [Online]. Available: http://www.who.int/cancer/detection/ breastcancer/en/index $2 . h t m l$.

Reeves GK, Kan SW, Key T, et al (2006). Breast cancer risk in relation to abortion: Results from the EPIC study. Int $J$ Cancer, 119, 1741-5.

Uyeturk U, Tatli AM, Gucuk S, et al (2013). Risk factors for stage IV breast cancer at the time of presentation in Turkey. Asian Pac J Cancer Prev, 14, 7445-9.

Vaisy A, Lotfinejad S, Zhian F (2014). Risk of cancer with combined oral contraceptive use among Iranian women. Asian Pac J Cancer Prev, 15, 5517-22.

Vessey M, Yeates D (2013). Oral contraceptive use and cancer: final report from the Oxford-Family Planning Association contraceptive study. Contraception, 88, 678-83.

Xing P, Li J, Jin F (2010). A case-control study of reproductive factors associated with subtypes of breast cancer in Northeast China. Med Oncol, 27, 926-31.

Zhang Q, Liu L-y, Wang F, et al (2012). The changes in female physical and childbearing characteristics in China and potential association with risk of breast cancer. BMC Public Health, 12, 368. 